\title{
Determination of Frictional Resistances of Deep Drawing Quality Steel Sheets in Bending Under Tension Test
}

\author{
Tomasz Trzepiecinski ${ }^{1}{ }^{*}$, Hirpa G. Lemu ${ }^{2}$ \\ 1 Department of Materials Forming and Processing, Rzeszow University of Technology, al. Powst. Warszawy 8, $35-959$ Rzeszów; Poland \\ 2 Department of Mechanical and Structural Engineering and Materials Science, University of Stavanger, N-4036 Stavanger, Norway
}

\begin{abstract}
Among many friction tests, the bending under tension (BUT) test simulates the frictional conditions on rounded edge of punch in deep drawing operations. The experimental evaluation of coefficient of friction value has been carried out using a special tribological simulator. Two friction conditions i.e. dry friction and lubrication were analysed. As a test material the deep drawing quality (DDQ) steel sheet commonly used in automotive industry was selected. The mechanical properties of the sheets were selected in the uniaxial tensile test. The experimental results show that the friction coefficient value is very stable after reaching a certain value of sheet deformation. It was found that an increase of rolls surface led to an increase of the sample elongation value at which exists the maximum effectiveness of lubricant. It was also observed that an increase of the amount of sample elongation decreases the sheet surface roughness and friction behaviour changes as a result of high contact pressure and plastic deformation of surface asperities.
\end{abstract}

Keywords: deep drawing; friction; friction coefficient; sheet metal forming.

\section{Introduction}

Friction in sheet forming processes is a complex function of material properties, process parameters, surface topography both of sheet metal and tools, and lubrication conditions. The friction occurring at high pressure values can significantly differ from the phenomena occurring at low loads due to the high impact of plastic deformations that may intensify many phenomena in the asperities contact zone. High pressure leads to greater tendency to frictional connections, which in turn increases the frictional resistance leading to increased wear. One of the most important factors affecting the value of friction resistance is surface topography. Review of the literature [1-3] regarding the impact of roughness parameters on the value of the coefficient of friction confirms that, depending on the nature of the contact, each parameter, such as the roughness of the cooperating surfaces and the material type, has a smaller or larger influence on the frictional resistance.

The main factors affecting the tribological phenomena in sheet extrusion processes are macro- and micro-contact, character of loads (static or dynamic), and temperature $[4,5]$. In order to comprehensively describe the role of friction, the concept of tribological system is developed [6], which consists of four main elements: a friction pair (deformed metal and tool), a third body (e.g. grease), a control system and macro and micro-environment. The last component of the tribological system consists of the machine and environmental conditions, such as humidity, temperature, dustiness and vibrations. During the friction process, friction connections are created, which are destroyed during the movement [7-9]. The type 
of friction connections between asperities to be created depends on the materials of the friction pair, in particular on their shear strength. High values of deformation and temperature increase in the micro-contact areas favor the formation of non-diffusion adhesive connections.

Bending Under Tension (BUT) developed by Littlewood and Wallace [10] attributable to friction modeling on the rounded edge of the die. The test consists in drawing a strip of sheet metal around a cylindrical counter-sample (Fig. 1). The BUT test allows to determine not only the value of coefficient of friction, but also its change during the process of deformation of the sample. This change may be related to the change of the surface topography of the sheet as a result of deformation and the change of contact conditions related to the strain hardening of the sample material [1]. Recent studies have shown that many factors have an effect on the coefficient of friction in a variety different manners. The literature contains numerous numerical and experimental investigations of a wide range of both die and workpiece materials, bend ratio and lubrication conditions.

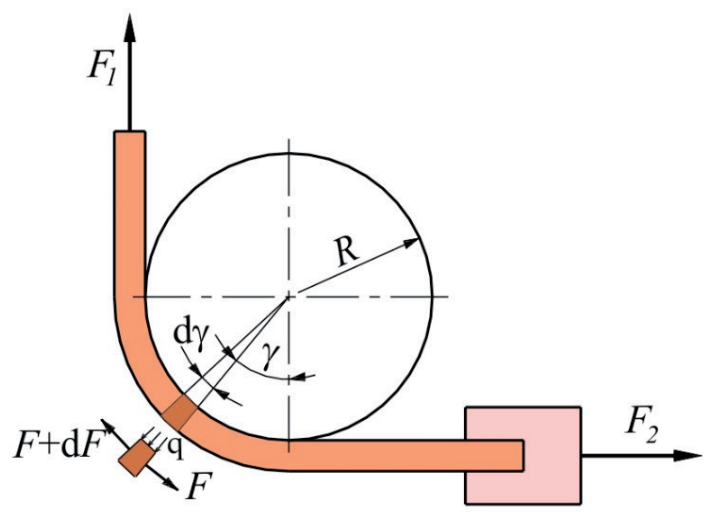

Fig. 1: Forces acting on an elementary section of the strip.

Melander et al. [11] used BUT machine for numerical and experimental evaluation of spring back in sheet metal forming. The ability of achieving high strains by combined bending and stretching in continuous BUT test is studied by Hadoush et al. [12]. In recent paper, Lemu and Trzepieciński [13] studied the frictional resistances of CuZn20 and AA5754 H24 sheets using bending under tension simulator. In numerical tests, the bending test of the bending sheet [13] analyzed with focus on the pressure distribution and the influence of the friction conditions on the deformation character of the sheet during its stretching around the cylindrical countersample. It was found that in the case of large unit pressures, the dominant influence on the deformation distribution in the contact zone is the countersample geometry. Tribological conditions in deep drawing using BUT at elevated temperature were investigated numerically by Ceron et al. [14]. Moghadam et al. [15] applied the acoustic emission technique in BUT testing for assessment of tribological conditions during sheet forming with an objective of determining the onset of galling. Andreasen et al. [16] developed a special BUT transducer in which friction around the tool radius can be directly measured when drawing a sheet strip around cylindrical pin under constant back tension. Analytical models for determination of frictional resistances on die drawing edge by strip drawing test have been developed by Evin et al. [17] In another work, Evin et al. [18] evaluated the friction coefficient at drawing edge of die by using modified Ouehler formula. Folle and Schaeffer [19] have also investigated the contact pressure in bending under tension test by a pressure sensitive film. In this paper the experimental evaluation of coefficient of friction of DDQ steel sheet value has been carried out using a tribological simulator. Two friction conditions i.e. dry friction and lubrication were analysed.

\subsection{Material}

\section{Experimental Section}

In this research, a deep drawing quality steel (DDQ) sheets with a thickness of $1 \mathrm{~mm}$ were examined. A tensile test in the universal testing machine was carried out to determine the mechanical properties. The mechanical properties of the sheets were determined in uniaxial tensile test using universal testing machine. The samples were cut in two orthogonal directions: along the rolling direction $\left(0^{\circ}\right)$ and transverse to the rolling direction $\left(90^{\circ}\right)$. The following basic mechanical parameters were determined (Table 1): yield stress $R_{p 0,2}$, strain hardening coefficient $C$ and strain hardening exponent $n$. Table 1 also shows the basic roughness parameters, i.e. arithmetic average height $R a$, root mean square roughness $R q$ and maximum height of the profile $R t$ determined using Surtronic $3+$ instrument manufactured by Taylor Hobson. 
Tab. 1: Basic mechanical parameters and surface roughness parameters of sheets tested.

\begin{tabular}{|l|c|c|c|c|c|c|}
\hline Sample orientation & $\begin{array}{c}R_{p 0,2} \\
\mathrm{MPa}\end{array}$ & $\begin{array}{c}\mathrm{C} \\
\mathrm{MPa}\end{array}$ & $n$ & $\begin{array}{c}R a \\
\mu m\end{array}$ & $\begin{array}{c}R q \\
\mu m\end{array}$ & $\begin{array}{c}R t \\
\mu m\end{array}$ \\
\hline $0^{\circ}$ & 170 & 385 & 0.16 & 1.64 & 2.13 & 11.3 \\
\hline $90^{\circ}$ & 160 & 369 & 0.15 & 1.79 & 2.41 & 11.9 \\
\hline
\end{tabular}

\subsection{Method}

The BUT tests were carried out by using the test setup shown in Fig. 2. A test strip was held at one end in a grip supported by a load cell. The flat sample with a width of $10 \mathrm{~mm}$ is wrapped around a cylindrical fixed roll and loaded in a tensile testing machine. The test was carried out using four rolls with a diameter of $20 \mathrm{~mm}$ made of tool steel. The surface roughness of rolls was characterized by arithmetic average height $R a$ with the value of 0.32 , $0.63,1.25$ and $2.5 \mu \mathrm{m}$ measured parallel to the roll axis.

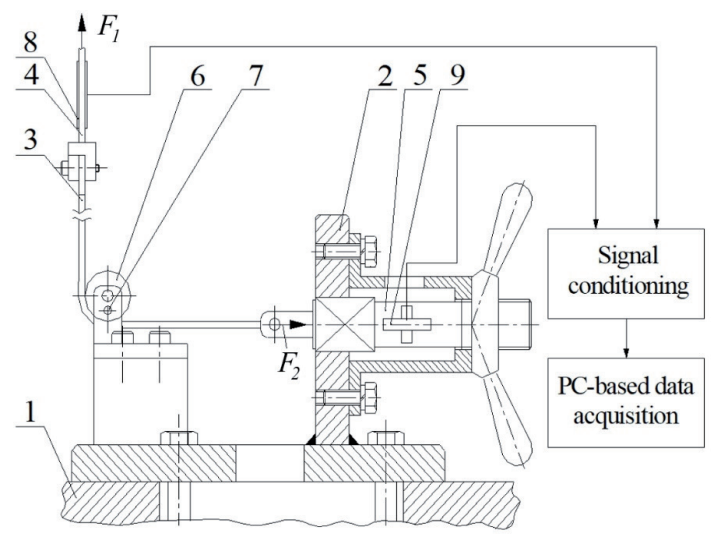

Fig. 2: Schematic view of testing device: 1 - machine base, 2 - device frame, 3 - specimen, 4 and 5 - tension members, 6 working roll, 7 - fixing pin, 8 and 9 - extensometer.

The occurrence of frictional resistance between the sheet metal and roll causes that the value of tensile force $F_{1}>F_{2}$. The forces $F_{1}$ and $F_{2}$ were measured simultaneously during the test and the coefficient of friction is determined according to the formulae:

$\mu=\frac{2}{\pi} \ln \left(\frac{F_{1}}{F_{2}}\right)$

Constant stretching speed, which is the speed of the test machine head, is equal to $0.3 \mathrm{~mm} / \mathrm{s}$. The tests were carried out until fracture of the specimen. Before friction testing, both rolls and samples were degreased using acetone. As lubricant, the conventional machine oil LAN-46 was used.

\section{Results and Discussion}

Friction coefficient value is quite stable in the analysed range of specimen elongation $\varepsilon$ evaluated using formulae:

$\varepsilon=\frac{\left(l_{0}+l_{g}\right)-l_{0}}{l_{0}}=\frac{l_{g}}{l_{0}}$

where: $l_{0}$ - length of the sample between grippers, $l_{g}$ - displacement of upper grip of testing machine.

In general, increasing surface roughness of rolls increases the friction coefficient value (Fig. 3). In the case of dry friction conditions, the smallest values of frictional resistances are observed for the rolls with surface roughness of $R a=0.32 \mu \mathrm{m}$. In this case, shearing of asperities does not affect significantly in terms of increasing the frictional resistance. The higher roughness of roll the more hard asperities of the roll surface intensify galling process. For the roll with roughness of $2.5 \mu \mathrm{m}$, on the other hand, the high height of profile causes that the real contact area of the sheet and tool surface is relatively small. It should be noted that the contact area between the sheet strip and countersample in BUT test is smaller than the area calculated geometrically. This is also true according to the observations of Folle and Schaeffer [19]. This is the case in metal forming because the frictional resistance of high deformations of the formed body depends on the contact area. It causes that the friction coefficient value of rolls when $R a=2.5 \mu \mathrm{m}$ is smaller than in the case of countersample with roughness $R a=1.25$ $\mu \mathrm{m}$. Asn a result of application of lubricant, the rolls with $\mathrm{Ra}$ in the range between 0.32 and $1.25 \mu \mathrm{m}$ are observed to have local minimum friction coefficient value at the sample elongation $\varepsilon=0.08-0.12$ (Fig. 4). In contrast, the countersample characterized by the highest value of $R a$ parameter is observed to have maximum value of friction coefficient in the mentioned range of sample elongations.

To analyse the effectiveness of lubrication the $L$ factor was introduced, defined as follows:

$$
L=\frac{\mu_{d}-\mu_{o}}{\mu_{o}} 100 \%
$$

where: $\mu_{d}-$ friction coefficient determined at dry friction conditions, $\mu_{o}-$ friction coefficient 


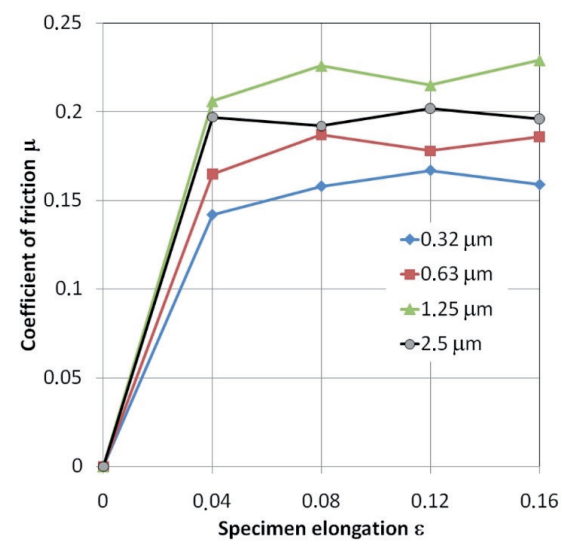

Fig. 3: Effect of specimen elongation on the value of friction coefficient determined at dry friction conditions.

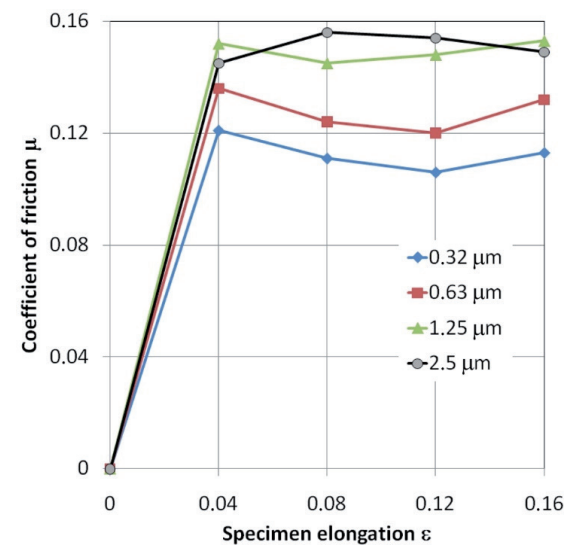

Fig. 4: Effect of specimen elongation on the value of friction coefficient determined at lubricated conditions.

determined at lubricated conditions.

For all used rolls, the maximum peak of effectiveness of lubrication is observed. Increasing surface roughness of rolls led to an increase of the sample elongation value at which the maximum effectiveness of lubricant is obtained. For the most roughened surface of roll, the $L$-value is the highest for sample elongation $\varepsilon=0.04$ (Fig. 5). Although the higher surface roughness of roll ensures the high volume of the valleys which entraps the lubricant, the mechanism of mechanical roughening of asperities is dominant. The highest effectiveness of lubrication is obtained for the countersample with $R a=0.32 \mu \mathrm{m}$ and sample elongation of $\varepsilon=0.12$. At these conditions, the beneficial volume of oil pockets entrap the lubricant which was supplied into the contact area with an increased value of sample elongation. Depending on the surface roughness parameter Ra value of the countersample, the use of lubricant reduces the friction coefficient by about $15-37 \%$. The use of tools with a low surface roughness value to reduce the frictional resistance seems unjustified because, in this case, the increased actual contact surface increases the interatomic interaction of the cooperating surfaces and in this way increasing the value of the friction coefficient.

During the BUT test, the sheet strongly resists deformation and is subjected to strain hardening phenomenon [2]. Increasing the amount of sample elongation decreases the sheet surface roughness and friction behaviour changes as a result of plastic deformation of surface asperities and high normal pressure. The topography led to continuous evolution as an influence of plastic deformation and flattening of asperities as a result of high contact pressures around the countersample circumference.

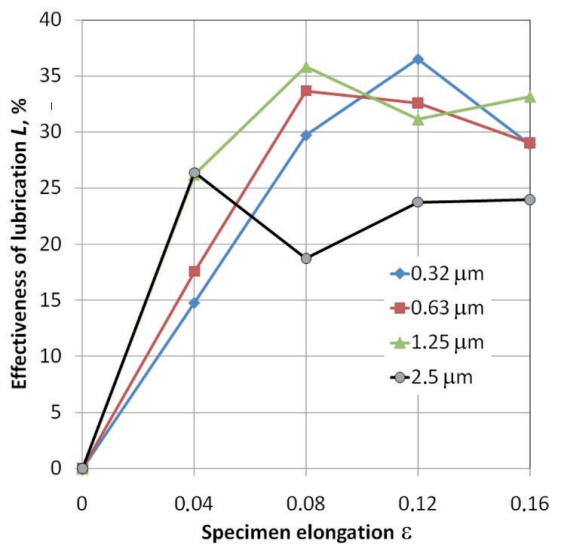

Fig. 5: Effect of specimen elongation on the effectiveness of lubrication.

As found by Trzepieciński and Fejkiel [1] increasing the sample deformation increases the sheet surface roughness, and as a consequence, the frictional resistance increases due to intensification of the roughness flattening mechanism. The highest value of frictional resistance at dry friction conditions, for all sample elongations, is registered for countersample roughness of $R a=1.25 \mu \mathrm{m}$ (Fig. 6). In the case of high surface roughness, the load pressure acts on the asperities, which results in a higher degree of surface flattening and increased frictional resistance.

In the case of high surface roughness of the countersample, the mechanism of ploughing can increase the frictional resistances. Application of 


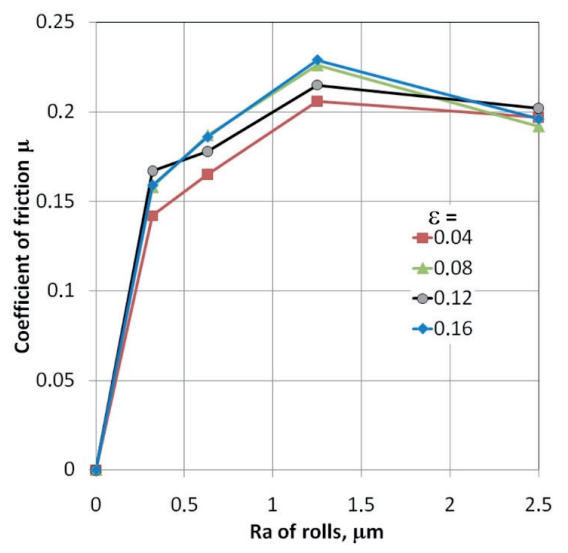

Fig. 6: Effect of roughness of rolls on the value of friction coefficient at dry friction conditions.

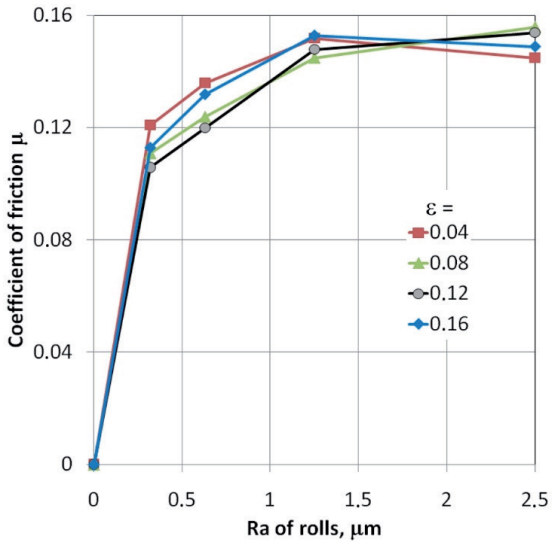

Fig. 7: Effect of roughness of rolls on the value of friction coefficient at dry lubricated conditions.

lubrication stabilizes the friction coefficient value in the range of countersample roughness $R a$ between 1.25 and $2.5 \mu \mathrm{m}$ (Fig.7). The real contact area is smaller than the nominal surface and depends on the surface roughness of the roll and sheet, tendency to strengthen the surface asperities, and the geometry of the contact area. This makes it difficult to generalize and interpret the obtained changes in the friction coefficient value. The load pressure between the materials of friction pair are transferred through the micro-areas of the real contact. In these areas, complex states of triaxial compression arise and the yield stress in surface asperities are exceeded. This causes an increase in tangential stresses and a local increase in temperature in the micro-areas of the contact. This situation of large deformation and high temperature favors the formation of non-diffusion adhesive joints that increase friction resistance.

\section{Conclusions}

In this paper, the frictional resistances of deep drawing quality steel sheets in deep drawing process were examined experimentally. The experimental results allow the following conclusions to be drawn:

$\checkmark$ value of friction coefficient is quite stable in the analysed range of specimen elongation and countersample roughnesses.

$\checkmark$ increasing surface roughness of rolls led to increase of the sample elongation value at which the maximum effectiveness of lubricant is found.

$\checkmark$ the highest effectiveness of lubrication is obtained for the countersample with $R a=0.32 \mu \mathrm{m}$ and sample elongation of $\varepsilon=$ 0.12 .

$\checkmark$ depending on the surface roughness parameter Ra value of the counter-sample, the use of grease reduces the friction coefficient up to $37 \%$.

$\checkmark$ increasing the amount of sample elongation decreases the sheet surface roughness and friction behaviour changes as a result of plastic deformation of surface asperities and high contact pressure. $\checkmark$ in the case of high surface roughness, the load pressure acts on the asperities, which results in a higher degree of surface flattening and increased frictional resistance.

\section{References and Notes}

[1] Trzepieciński, T., Fejkiel, R. (2017). On the influence of deformation of deep drawing quality steel sheet on surface topography and friction. Tribology International, 115, 78-88.

[2] Trzepieciński, T., Bazan, A., Lemu, H.G. (2015). Frictional characteristics of steel sheets used in automotive industry. International Journal of Automotive Technology, 16, 5, 849-863.

[3] Hol, J., Cid Alfaro, M.V., de Rooij, M.B., Meinders, T. (2012). Advanced friction modeling for sheet metal forming. Wear, 286-287, 66-78.

[4] Zhou, Y., Zhu, H., Zuo, X., Li, Y., Chen, N. (2015). The nonlinear nature of friction coefficient in lubricated sliding conditions. Tribology International, 88, 8-16.

[5] Gil, I., Mendiguren, J., Galdos, L., Mugarra, E., de Argandoña, E.S. (2016). Influence of the pressure dependent coefficient of friction on deep drawing springback predictions. Tribology International, 103, 266-273.

[6] Kim, H., Kades, N. (2012). Friction and Lubrication. Altan, T., Tekkaya, A.E., Sheet metal forming. Fundamentals. ASM International, Materials Park, 89-104.

[7] Fleury R.M.N., Paynter R.J.H., Nowell, D. (2017). Estimation of the coefficient of friction in partial slip contacts between contacting nickel superalloys. Tribology International, 108, 156163.

[8] Davis, F., Sackey, M.N., Andrews, A., Owusu-Ofori S.P. (2017). Realistic friction coefficient model between a rolling cylindrical ele- 
ment and a deformable flat surface. Tribology International, 109, 252-257.

[9] Wang, C., Ma, R., Zhao, J., Zhao, J. (2017). Calculation method and experimental study of coulomb friction coefficient in sheet metal forming. Journal of Manufacturing Processes, 27, 126137.

[10] Littlewood, M., Wallace, J.F. (1964). The effect of surface finish and lubrication on the fictional variation involved in the sheet-metal-forming process. Sheet Metal Industry, 41, 9251930.

[11] Melander, A., Thoors, H., Stenberg, N., Ning, M. (2015). Spring back evaluation for high and ultra high strength sheet steels with the bending under tension machine. International Journal of Material Forming, 8, 1, 137-144.

[12] Hadoush, A., van den Boogaard, A.H., Emments, W.C. (2011). A numerical investigation of the continuous bending under tension test. Journal of Materials Processing Technology, 211, 19481956.

[13] Lemu, H.G., Trzepieciński, T. (2013). Numerical and experimental study of frictional behaviour in bending under tension test. Strojniški Vestnik-Journal of Mechanical Engineering, 59, 4149.

[14] Ceron, E., Martins P.A.F., Bay, N. (2014). Thermal analysis of bending under tension test. Procedia Engineering, 81, 18051810.

[15] Moghadam, M., Suleiman, M.H., Christiansen, P., Bay, N. (2017). Acoustic emission monitoring of the bending under tension test. Procedia Engineering, 207, 1421-1426.

[16] Andreasen, J.L., Olsson, D.D., Chodnikiewicz, K., Bay, N. (2006). Bending under tension test with direct friction measurement. Proceedings of the Institution of Mechanical Engineers, Part B: Journal of Engineering Manufacture, 220, 1, 73-80.

[17] Evin, E., Tomáš, M., Výrostek, M. (2012). Benchmarking of friction models used in the simulation of deep drawing. Annals of Faculty Engineering Hunedoara - International Journal of Engineering, 10, 2, 129-134.

[18] Evin, E., Németh, S., Vyrostek, M. (2014). Evaluation of friction coefficient of stamping. Acta Mechanica Slovaca, 18, 3-4, 20-27.

[19] Folle, L.F., Schaeffer, L. (2016). Evaluation of contact pressure in bending under tension test by a pressure sensitive film. Journal of Surface Engineered Materials and Advanced Technology, 6, 201-214.

\section{Biographical notes}

Dr hab. inż. Tomasz Trzepiecinski received his Ph.D., degree in machine building from Rzeszow University of Technology in 2006. Since 2009 he has been working as an Assistant Professor at the Department of Materials Forming and Processing, Rzeszow University of Technology, Rzeszów, Poland and became an Associate Professor in 2014. He is a member of European Mechanics Society and International Association of Engineers. His research interests include materials processing technology, friction modeling in metal forming and tribology of lubricated surfaces, numerical modeling of metal forming processes based on the finite element method, and computer-aided systems in design, analysis and manufacturing.

Dr. Hirpa G. Lemu received his MSc and PhD, degrees from the Norwegian University of Science and Technology (NTNU) in 1997 and 2002 respectively. He is currently serving as a Professor of Mechanical Design Engineering at University of Stavanger, Norway. His current research activities focus on simulation based design optimization, performance enhancement of energy conversion systems, multi-body dynamics simulation, analysis of material anisotropy, material modeling and analysis using finite element methods, additive manufacturing technology and simulation data management. 